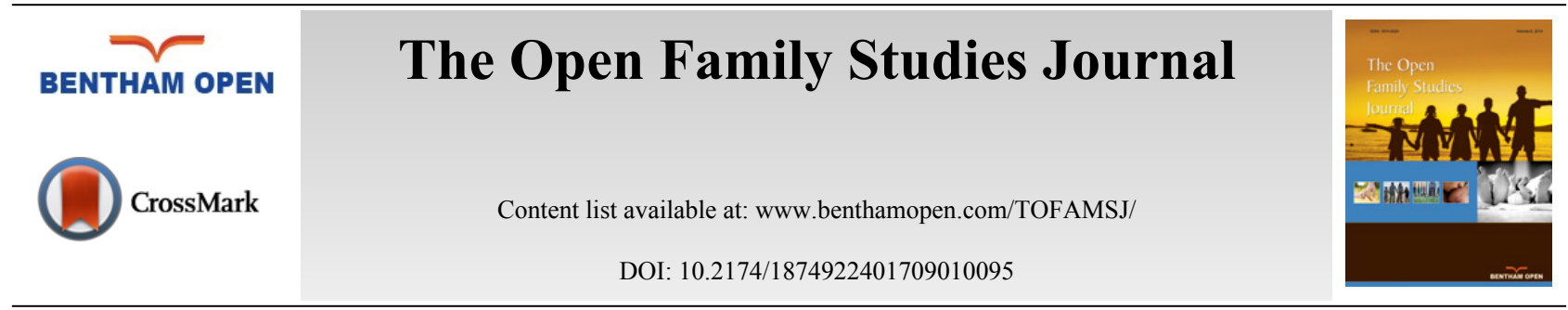

RESEARCH ARTICLE

\title{
The Introduction of Emotion Coaching as a Whole School Approach in a Primary Specialist Social Emotional and Mental Health Setting: Positive Outcomes for All
}

\author{
Licette Gus ${ }^{1, *}$, Janet Rose ${ }^{2}$, Louise Gilbert ${ }^{3}$ and Ryan Kilby ${ }^{4}$ \\ ${ }^{I}$ Independent Educational Psychologist, Gloucestershire, UK \\ ${ }^{2}$ Norland College, Bath, UK \\ ${ }^{3}$ Bath Spa University, Bath, UK \\ ${ }^{4}$ Meadow View Farm School, Leicestershire, UK
}

Received: June 30, 2017

Revised: August 14, 2017

Accepted: September 12, 2017

\section{Abstract:}

\section{Background:}

This paper describes the impact upon well-being of pupils, staff, and families following the introduction of Emotion Coaching as a whole school approach.

\section{Objective:}

This paper's objective is an attempt to redress the lack of published evidence about the use of Emotion Coaching in schools and to highlight how a school has been able to adopt a humanistic relational approach in a climate in which behaviorist principles are dominant in schools.

\section{Method:}

A case study approach using mixed methods was used. Data were examined from an outcomes model perspective where the benefits and changes intended from Emotion Coaching were the starting point. Perspectives from pupils, staff, and families were gained via interviews and structured questionnaires alongside quantitative measures of pupil academic progress and staff and pupil behavior.

\section{Results:}

Results indicate that Emotion Coaching improved the pupil's ability to regulate their feelings and had a positive effect upon teacherpupil relationships. Family-school relationships were supported by the school's use of and modeling of Emotion Coaching with families and the ethos of attunement and non-judgemental interactions implicit in Emotion Coaching. Emotion Coaching promoted an increase in shared emotional language and trust. Shared emotional language and trust were key in the development of both teacher-pupil and family-school relationships. There was an improvement in well-being in that: rates of pupil restraint decreased, pupils made better than expected academic progress, staff absenteeism reduced, and families reported improved family life.

\section{Conclusion:}

We conclude that Emotion Coaching contributes to the promotion of sustainable, holistic improvement in wellbeing for pupils, school staff, and families.

Keywords: Emotion Coaching, Social and emotional learning, Teacher-pupil relationships, Home-school relationships, Universal intervention.

\footnotetext{
* Address correspondence to this author at the Licette Gus Psychology 6 The Mansion, Northwick Park, Blockley, GLOS, GL56 9RJ, Gloucestershire, UK. Tel: +44 1386 700244, E-mails: emotioncoachinguk@gmail.com; licette.gus@gmail.com
} 


\section{INTRODUCTION}

The aim of this paper is to highlight the effectiveness of a humanistic approach, Emotion Coaching (EC) [1] to support the development of well-being of pupils, staff, and families in a special school for children with Social, Emotional, and Mental Health (SEMH) needs. Emotion Coaching is a relational style which provides a structured framework for adults to respond to children's 'in the moment' emotional needs. This paper is also a response to Sebba, Berridge, Luke, Fletcher, Bell, Strand, Thomas, Sinclair and O'Higgins's [2] report on academic progress in England among children who are Looked After, which concluded that Emotion Coaching is an initiative to support children with social, emotional, and mental health difficulties that needs to become more widely known ${ }^{1}$.

Considerable attention has been given to behavioral, cognitive behavioral, and systemic approaches to supporting children with social, emotional, and behavioral difficulties in schools [3, 4] and via home-school partnerships [5, 6]. However, there is much less published evidence to support the use of humanistic approaches in schools. Cooper and Cefai [3] suggested that this is because approaches from behavioral, cognitive behavioral, and systemic models have lent themselves to the development of formal intervention programmes that are easier to evaluate using quantitative methods. Humanistic approaches promote relational models that have been characterized as "ways of being" rather than as structures and frameworks [3]. They are relative in their interpretation, therefore, they have greater difficulty demonstrating replicable efficacy.

In England, the change in terminology in the 2013 Code of Practice of Special Educational Needs (SEN) [7] - which replaces the Behavior and Social Difficulties (BESD) category with social, emotional, and mental health difficulties (SEMH) - adds further impetus to viewing behavior in schools from a different perspective. SEMH promotes the use of the biopsychosocial paradigm [8] and accepts that behavior is the result of a child or young person's SEMH needs. This change in the Code of Practice for SEN [7] serves as a reminder for schools to evaluate the different approaches they take to support social, emotional, and mental health needs in their schools as a means to behavior management.

\subsection{Relational Approaches}

Relational approaches focus upon the relationships between individuals rather than locating the difficulty and solution within an individual - an emphasis on interpersonal rather than intrapersonal processes. Relational approaches in educational settings require a more robust evidence base. A child's relationship with key adults at home and school is a major determinant in their well-being [9] and McLaughlin and Clarke [10] emphasised the central role of the pupilteacher relationship. The relationship between these two settings also impacts the child [11]. The importance of using established, evidence-based practices in education is growing in line with schools' role in supporting pupil mental health and well-being [12]. Additionally, schools, as ever, appear to find it difficult to meet the needs of a proportion of their pupils: for primary aged pupils both fixed-term and permanent exclusions are increasing [13]. Moreover, traditional family-school interventions have encountered difficulties in engaging all families and maintaining program fidelity [14 - 16].

Ineffectual home-school relationships can be a barrier to family-school interventions, and these weak relationships can act as barriers to children's SEMH development. Dunst, Johanson, Rounds, Trivette and Hamby, Adams and Christenson and Francis, Blue-Banning, Haines, Turnbull, and Gross [17 - 19] concur that trust is vital in building and maintaining home-school relationships and that improved home-school communication is key in building trust. McCormick, Cappella, O'Connor and McClowry [20] suggested that 'processes' of the home-school relationship rather than practices need to be considered. Effective processes include: home-school communication being two-way [21], communication from school is proactive and positive rather than reactionary and punitive [22], and communication that emphasises similarities between home and school rather than differences [21,23]. Perceptions of similarities are enhanced with the sharing of emotions about a situation (or behavior) rather than discussions about the behavior and/or receiving comfort, validation, and support for emotions that are being experienced as a result of a particular situation $[24,25]$. Improving home-school relationships via trust and effective communication thus appears to be central to establishing effective home-school interventions to support children's SEMH development in a holistic manner.

Not only have behavioral, cognitive, behavioral, and systemic approaches been dominant over humanistic approaches, support to pupils with SEMH challenges has relied on targeted, discrete programs delivered by specialists. This may leave pupils with the majority of the school day (and week) to manage in the environment they found challenging. There is therefore also a need to examine how a whole-school, universal approach can support pupils, as opposed to targeted interventions for individuals. 


\subsection{Universal Approaches}

Jones and Bouffard [26] and Banerjee, Weare and Farr [27] suggest that interventions for pupils' social and emotional learning should be integrated into the daily life of the classroom rather than provided through discrete programs. The call for integrated universal support for pupils in schools is evidenced by meta-analyses that suggest that school staff are effective in delivering universal interventions to support pupil social and emotional learning [28, 29], and by a survey revealing effective practice in the promotion of emotional well-being in English schools [30]. Models are emerging that encompass these ideas of relational and universal approaches as well as targeted support to promote SEMH development in all children, including those with additional needs. Parker, Rose and Gilbert [31] describe Attachment Aware Schools (AAS), which reflect a humanistic, relational framework that promotes universal and targeted interventions in a pyramid of support to meet the attachment needs of all pupils. The model endorses Emotion Coaching as a whole school strategy. Emotion Coaching is a naturally occurring style of communication and interaction first observed by Gottman, Katz, and Hooven [1] in their longitudinal study of U.S. families. Gilbert [32] argued that Emotion Coaching is a technique as well as an approach, in that it can be used as a tool for specific "behavioral incidents," i.e. an intervention, as well as a generic communicative style that informs everyday interactions, i.e. a way of being.

\subsection{Emotion Coaching}

Within the biopsychosocial paradigm, Emotion Coaching is a humanistic approach to improving personal and collective well-being. Gus, Rose and Gilbert [33] proposed Emotion Coaching as a universal, simple, low-cost strategy for educational settings. Emotion Coaching enhances adult's communication skills in relating effectively with children and young people about emotions and behavior [34]. It is an approach to support the development of emotional regulation in children through attuned relationships. Gottman, Katz, and Hooven [35] noticed that children who were Emotion Coached during times of negative emotions displayed greater abilities to regulate the involuntary physiological processes of the autonomic nervous system. Children who were Emotion Coached displayed:

- self-soothing behavior;

- good attention and concentration;

- inhibition of actions when needed;

- quick recovery from stress;

As a result, Emotion Coached children:

- achieved more academically in school;

- are more popular;

- had fewer behavioral problems;

- had fewer infectious illnesses;

- were more emotionally stable;

- were more resilient;

Emotion Coaching emphasises noticing, empathising with, and validating a child's emotions that may contribute to the behavior before limit-setting and helping the child to problem solve. An important distinction is made between a child's behavior and the feelings that underlie the behavior, there is an acceptance that all emotions are valid; however not all behaviors are appropriate or acceptable. A critical aspect to Emotion Coaching is parental awareness of their own views and opinions of emotions in themselves and others, and this is known as parental meta- emotion philosophy [35].

Strong evidence for the benefits of Emotion Coaching to support children experiencing a range of emotional difficulties is found in clinical work with families, including those with children with conduct behavioral difficulties $[36,37]$, and it has been positively correlated with secure attachments [38]. Gus et al. reviewed this evidence of Emotion Coaching in families [33]. In England in educational and community settings, evidence for the use of Emotion Coaching is emerging. The bulk of evidence to date comes from Rose, McGuire-Snieckus and Gilbert [34]. No randomized trials or longitudinal studies have been conducted in a professional context. Moreover, there lacks a study that investigated how concurrent EC implementation - at home and at school - is supportive for children.

Findings of Rose et al. are consistent with those found in parental clinical settings [34]: Adult's meta-emotion philosophy changed as a result of Emotion Coaching training, which enabled increased adult self-regulation. Disruptive 
behavior decreased and pro-social behavior increased in children and young people. The need for the use of rewards and sanctions in schools was reduced. Social and emotional competencies were increased and Rose et al. [34] suggested that this related to an improvement in the children and young people's stress response system and an ability to process their emotional experiences. Other ways that emotional competencies may be increased by Emotion Coaching is through the use of language to label emotions [39]. Theories of attachment suggested that self-esteem as an emotional competency may be improved by children forming more secure attachments a result of attunement and empathetic interactions characteristic of Emotion Coaching [40, 41].

The inter-personal nature of Emotion Coaching facilitates individual adoption and application. However, Parker et al. [30] noted that there are few instances of the impact of whole school adoption of the approach; perhaps because of the difficulty reconciling the humanistic basis of EC with the current, dominant behaviorist principles endorsed by government policies [42 - 44] and processes [44].

The Attachment Aware Schools (AAS) Project [31] uses Emotion Coaching as a key aspect of the program to support the emotional and social development of all children. An evaluation report of this program using mixed methods [45] identified that over one year there were significant improvements in pupil academic achievements, a decrease in use of sanctions, a decrease in exclusions, and a decrease in hyperactivity and overall difficulties, as measured by the Strengths and Difficulties Questionnaire (SDQ). Professionals reported increased skills, confidence and understanding, and a more consistent approach to responding to students. The report stressed that a key feature for success of Emotion Coaching and AAS was the change of practice for the adult.

\section{METHODS}

This study draws from the paradigms of case study [46 - 48] and outcome evaluation [49 - 51]. Case study concerns a specific instance or manifestation of the phenomenon and is most suitable when there are identifiable, relatively selfcontained units to analyze that have boundaries that can be defined [52]. Since case study methodology is flexible, convenient, necessitates few resources, it is often used in educational settings to capture snap-shot examples, which can then be analyzed [53]. Case studies can evidence typical instances to reveal generalizable qualities which can then be applied to other similar situations and act as a contrast to the norm. Therefore, it can test theory development or can be used to increase the credibility of theory through falsification [48, 52, 54, 55].

Case study methodology allows the researcher to explicitly focus on relationships and processes [56]. Therefore, the overarching research question, 'how pupils, staff, and family well-being were affected as a result of the introduction of Emotion Coaching can be viewed as describing (how was well-being affected) a social process (Emotion Coaching) in a school (the subject). The aim is to reveal the complex relationships and processes pertinent to pupil, staff and family well-being within the school community. However, because of a relative dearth of knowledge about Emotion Coaching as a whole school approach, a mixed methods case study design [57] was adopted; this permitted a comprehensive view of the situation. The use of quantitative and qualitative data enhances 'triangulation of data' and is characteristic of case study research [48]. Data was therefore gathered from school leaders, staff, pupils and parents within the school community. A variety of methods were used, including interviews, routine statutory school tracking data, questionnaires and formal feedback following Emotion Coachin training and pupil's start to the school year.

Friedman's Outcomes Based Accountability (OBA) framework [49] has been used extensively within UK Local Authorities to improve outcomes for all children and young people [50, 58, 59]. Outcomes Based Accountability evaluation was considered appropriate to use as mixed methods are inherent in Friedman's framework, and there is a desire to position this study within the wider context of evidence-based government policy and commissioning work. Therefore, 'is anyone better off?', which is one of Friedman's three simple questions in his performance framework [49], was used to frame the evaluation outcomes.

\subsection{School Context}

The subject of this case study is an independent day special school for children aged 5-11 years experiencing SEMH issues. The school opened in 2011 and moved to its present site in 2013. The school had 25 pupils on roll (now increased to 35), is located on a farm small-holding ${ }^{2}$, and the farm facilities form part of the school provision. It has a 'no-exclusion', 'full-time education' policy and aims to work with children to enable them, if appropriate, to return to a mainstream or local area special school setting. Twenty-five percent of the children are from disadvantaged backgrounds and all pupils have a statement of special educational needs or an education, health, and care plan. A number of pupils have autistic spectrum conditions. 
The specialist nature of the school mean that most children do not live locally, and they travel to school in taxis. Prior to starting at this specialist provision, many of the children had not been attending school or they had been attending school on part-time timetables due to their school being unable to meet their special educational needs. A fulltime family support worker is employed by the school.

Prior to 2013, the school had been following a traditional behavioral-based way of supporting pupil progress: for example, using rewards, choice, and natural consequences [42]. However, unease about how this approach did not seem to support the emotional difficulties experienced by the pupils led to all the Senior Leadership Team (SLT) attending an Attachment and Trauma training course. As a result of the training, SLT decided to implement a different approach to support the development of their pupils' behavior and learning. An attachment-informed relational approach was implemented, using Emotion Coaching as the basis for communication and teaching about emotions.

Information was disseminated to school staff via in-house training that was delivered by the SLT. Initially, staff were encouraged to focus using Emotion Coaching with one particular child. Built into the implementation of the project was a variety of on-going staff support including: SLT modelling Emotion Coaching, providing scripts for staff to use if needed, positively noticing when other staff members used Emotion Coaching, group discussions, and personal one-to-one supervision.

Once Emotion Coaching was embedded as an approach used by all school staff, Emotion Coaching was cascaded to the families. This occurred via school staff modeling Emotion Coaching in their interactions with families, individual support for families in using Emotion Coaching with their children, and through family group training/information sessions at school.

\subsection{Data Collection}

A mixed methods design was appropriate for this research from an ethical perspective. The subject of this case study was a Social, Emotional, and Mental Health (SEMH) specialist provision for primary school pupils. The nature of this provision meant that individual vulnerability and the possibility of discomfort or harm to pupil, staff, and family members needed additional consideration. To ensure no harm or discomfort was experienced by pupils, staff and families, the lead researcher only interacted with the Head Teacher (HT). Any information gathered directly from members of the school community was collected by this known, trusted, and respected teacher. The HT acted as a formal gatekeeper between the researchers and the school community. In addition, consent was sought by the gatekeeper on each occasion when new data was collected. All data were anonymised by the gatekeeper.

Two semi-structured interviews were conducted by the lead researcher with the Head Teacher at a one year interval. The first interview focused upon the implementation of Emotion Coaching with staff members and the second interview related to how Emotion Coaching was used with families. As a result of these interviews, additional data were collected from the school. (See Appendix A for the Interview Protocol.)

Pupil data related to behavioral and academic progress data, qualitative data from staff responses on a questionnaire [34], and pupil structured reflections. The pupil reflection was with the HT following the use of Emotion Coaching. Pupils were asked to reflect on identifying what the adult helped them to do, what the adult did that helped that to happen, and what the pupil was able to do as a result of the interaction.

Staff perspectives of Emotion Coaching were gained via the Emotion Coaching Exit Questionnaire (ECEQ) [34]. The ECEQ was developed by Rose et al. [34] as a tool to obtain feedback from those using Emotion Coaching in their work with children. It gathers information on personal emotional understanding (meta-emotion) and self-regulation, and the impact of Emotion Coaching on the child, in particular, emotional and behavioral self-regulation. The ECEQ comprises 24 items with Yes/No response options as well as semi-structured open response questions. The semistructured questions asked for participant's views on the effects of Emotion Coaching on practice as well as identifying specific benefits and challenges of applying Emotion Coaching in practice. Staff data relating to sickness and absences were also examined.

Information from families was collected in several ways. Semi-structured telephone interviews were conducted by the HT using an interview protocol (See Appendix B). The remaining data formed part of the school's routine data collection and feedback process. This included written feedback data from families which focused on how their child had settled into school, parent evaluation forms following Emotion Coaching training/information sessions at school, and letters to the school from families relating to Emotion Coaching. 


\section{RESULTS}

In this article quantitative and qualitative information is presented separately. During the initial interview with the HT, aspects of everyday tracking information collected by the school was collated and later analysed. This included, the number of occasions pupils needed to be physically restrained by staff, pupil academic progress and staff absences. Responses to closed answers questions contained within the ECEQ were collated to give an indication of impact upon professional practice and staff personal self-regulation. This quantitative information provided the starting point for the collection of qualitative data; to help explain the observations and allow for the individual experiences to be understood in context [57]. Responses to the open ended questions in the ECEQ were analysed to illuminate the benefits for staff, benefits for pupils and benefits to the pupil-adult relationship. Pupil perspective on what occurred during and as a result of Emotion Coaching was sought. The impact of Emotion Coaching for families was analysed in terms of the homeschool relationship and family life.

\subsection{Quantitative Benefits to Pupils and Staff}

\subsubsection{Pupil-staff Behavior}

Data on the number of occasions pupils needed to be physically restrained by staff was collected for all pupils who attended the school over three time periods:

Time $1(\mathrm{~T} 1)=$ the term before the introduction of Emotion Coaching (Autumn term 2013): Total number $=75$

Time $2(\mathrm{~T} 2)$ = the term after the introduction of Emotion Coaching (Spring term 2014): Total number $=48$

Time 3 (T3) = the second term after the introduction of Emotion Coaching (Summer term 2014): Total number $=33$

A related t-test was conducted to evaluate if there was a significant decrease in the use of physical restraint following the introduction of Emotion Coaching. There was a statistically significant decrease in the number of occasions physical restraint needed to be used from $\mathrm{T} 1$ to $\mathrm{T} 2 ; \mathrm{t}=2.4558, \mathrm{df}=7, \mathrm{p}<0.025$. Between $\mathrm{T} 1$ to and $\mathrm{T} 3$, the reduction in use of restraint remained statistically significant, $t=3.006, \mathrm{df}=7, \mathrm{p}<0.01$. There was no significant difference between $\mathrm{T} 2$ and $\mathrm{T} 3, \mathrm{t}=0.99, \mathrm{df}=7$. The reduction in use of physical restraint found between $\mathrm{T} 1$ and $\mathrm{T} 2$ was maintained and became the new norm.

\subsubsection{Pupil Academic Progress}

Following the introduction of Emotion Coaching at the school, the academic progress of 10 pupils was tracked over two years (2013-2015). National Curriculum levels were being used nationally at the time and government guidelines expected that children would make 3 sublevels (equating to one level) of progress every two years for Reading, Writing, and Mathematics. In 2011/12, 93\% of children with no identified special educational need made the expected progress in English and $92 \%$ did so in Mathematics. By contrast $46 \%$ of pupils with statements of special educational needs made the expected rate of progress in English, whilst $45 \%$ achieved this in Mathematics. $78 \%$ of children with behavioral, emotional, and social difficulties in mainstream schools made the expected rate of progress in English, whilst $73 \%$ did so in Mathematics [60].

The data relating to the reading, writing, and mathematics progress of the 10 children who were at the case study school for two years is shown in Appendix C. Following the introduction of Emotion Coaching, children made on average 6.44 sublevels of progress with reading, 3.88 sub-levels of progress with writing and 4.88 sublevels of progress for Mathematics. Data captured regarding nationally expected progress for all primary-aged children were used as the control measure for statistical analysis of the data. A matched t-test for unrelated samples was conducted for each skill area to check for significance in the progress achieved by pupils at the special school compared to national expectations. For reading, $\mathrm{t}=4.61, \mathrm{df}=9, \mathrm{p}<0.0006$ (one-tailed test), therefore, the pupils made statistically significant better than expected progress with reading over two years. For writing, $t=1.395, \mathrm{df}=9, \mathrm{p}<0.098$ (one-tailed test), there was no significant difference in the rate of writing progress between that expected nationally and those pupils in the school. For numeracy $\mathrm{t}=4.47, \mathrm{df}=9, \mathrm{p}<0.0007$ (one-tailed test), pupils at the school made statistically better than expected progress in mathematics. Pupil academic progress matched or was greater than that expected by national standards following the introduction of Emotion Coaching.

For four of the pupils, it was possible to seek academic progress data for the two years preceding the introduction of Emotion Coaching. This data gave a stronger indication of the contribution of the change of approach to the pupil's progress. Data for two of the children were lost in the move of school location (and the children no longer attended the 
school). Of the remaining two, the progress of one child was inappropriate to use, as he had a deteriorating medical condition and was often absent from school. However, data for one child (child 5) evidenced 3 sublevels progress with reading before Emotion Coaching followed by 8 after, 2 sublevels levels with writing compared to 7 after Emotion Coaching was introduced, and 2 sublevels with numeracy before making 6 sublevels of progress after Emotion Coaching was introduced as an approach in the school. This child's academic progress accelerated once Emotion Coaching was introduced.

\subsubsection{Staff Confidence and Absences}

During the interview with the HT about how attitude, opinion, and behavior of staff had changed since the introduction of Emotion Coaching as a whole school approach, improvement in general staff calmness and feelings of competency were frequently mentioned. Staff attendance records, $(n=20)$ in the year preceding the introduction of EC as a whole school approach and for the year after were compared as indicators of staff stress levels. These records revealed staff absences reduced from 83 to 63 days, a decrease of 24\%. 9 members of staff completed the ECEQ during one afternoon at school at the end of a staff meeting. All participants completed the 24 Yes/No response items, and there were 216 positive responses and 0 negative responses. School staff felt Emotion Coaching had been very effective in terms of their own professional practice, personal self-regulation, and behavioral impact upon the child. This is consistent with the findings by Rose et al. [34, 45].

\subsection{4.. Benefits for Pupils, Staff and Families (Qualitative)}

The open-ended responses questions on the ECEQ $(n=9)$ were analysed to search for benefits for staff, benefits for pupils, and benefits to the relationship between pupils and adults in school. Responses were then analysed in two ways. Themes were identified from initial coding. Responses were also analysed a second time using a template approach [61]. Responses were categorised according to Friedman's [49] "better offness" measures; evidence of increase of knowledge/skills, attitude/opinion, improvements/changes in behavior or circumstance for staff or pupils. This second analysis served to confirm the themes from the thematic analysis but also aided in the development of connections between themes.

\subsubsection{Benefits for Staff}

The legacy from the comprehensive and consistent whole school training, and the support surrounding attachment and the effects of trauma, is evidenced by the language staff used in their ECEQ responses. The over-arching theme that emerged from staff responses about the personal benefits of using Emotion Coaching with pupils was a sense of improved ability to support their pupils. Three sub-themes emerged: Self efficacy, emotional skill development and personal action. Staff felt a sense of unity with each other and a greater degree of personal self-efficacy i.e. calm, confident and controlled when dealing with children. Development of staff empathic skills were indicated by reports of trying to think about why a child may be acting the way they do Emotion Coaching "helps me to find out, understand and then resolve actual issues rather than just deal with behaviour". Personal action was a sub-theme relating to staff feeling that they were better able to support their pupils. Staff behaviors changed in that they reported being more proactive, vigilant, and using the Emotion Coaching scripts/supports provided by SLT "the script helped me to de-escalate potentially difficult situations with children".

\subsubsection{Benefits for Pupils}

An over-arching theme that emerged from staff responses of the ECEQ was change - both within the pupils and to the school environment. As a result of Emotion Coaching, pupils were better able to regulate their feelings, which was referenced as 'within pupil change'. There were also positive changes to the school communicative and emotional environment as a result of adults adopting a whole school approach to Emotion Coaching. Within pupil change was highlighted by the development of emotional literacy, "children understand their emotions more", the pupils are able to process their feelings "most children have been able to calm down much quicker when they have had the emotions labelled and explained to them" and pupil empathy developed as the pupils start to be able to see situations from different perspectives. A second within pupil change was an increase in communication and trust in adults, "pupils speak more to adults about what is upsetting them/making them angry". As a result of this improvement in communication and trust "children are more likely to express their feelings through speech rather than actions" and start to be able to accept praise and positive events. Staff perceived that the emotional environment of the school changed for the pupils. Staff felt that they were acting as emotional teachers and a 'safe place' for pupils "labelling the child's 
emotions helps in calming the child and make them feel safe".

Adult support with labelling and explaining emotions helped pupils to better understand and manage their emotions, Fig. (1) highlights 'within child' features that enable this to occur, as well as supportive, key environmental factors.

Fig. (1). Within child and environmental factors that improves a child's ability to regulate their feelings as a result of EC.

This theme of Emotion Coaching promoting change was supported by direct reports from pupils. Following instances when Emotion Coaching was used by the HT, pupil's voice was captured through structured reflection. Reflections were gained from 6 pupils, which consistently identified that, as a result of Emotion Coaching, their mood/emotion changed. For example, one pupil said "I'm not so mad, he calms me down and he makes me not worry so much". Another said, "I feel calm". Pupils were able to identify that it was because the teachers conveyed an understanding of their feelings (empathy) and offered them an explanation (validation of feelings) that helped them feel that way, "he (teacher) talks to me about what I am angry about and explains why I am angry and worried". The pupils all believed that, as a result of Emotion Coaching, they were able to return to their classwork, "I can go back to class and get on with my work", "I get on with my work, get on with my day because we have talked through my anger". One pupil said that as a result of Emotion Coaching he can do, "loads of things (like) writing, walking and lessons - Science and Maths - I'm really good at Maths now".

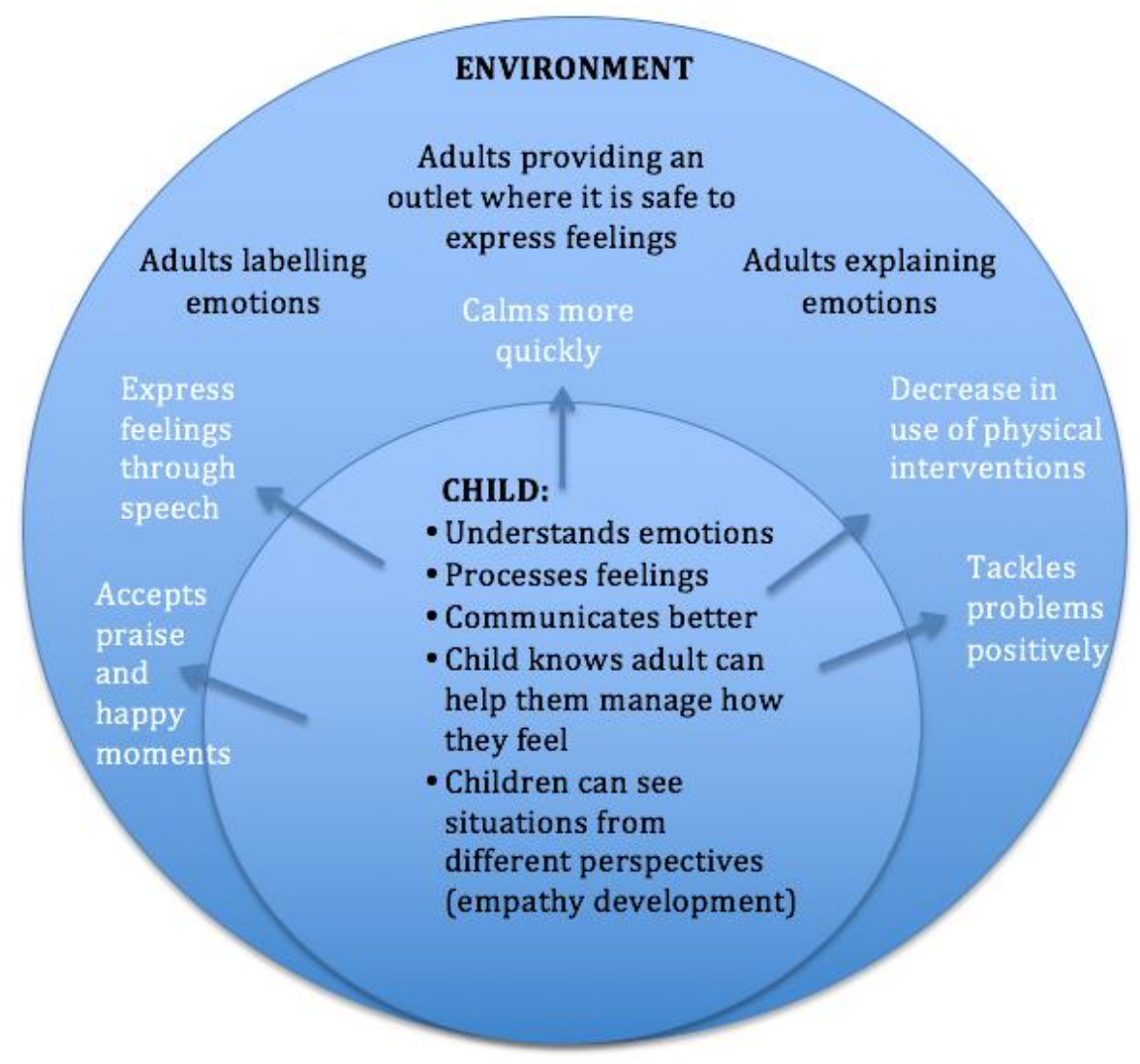

Fig. (1). Within child and environmental factors that improves a child's ability to regulate their feelings as a result of EC.

\subsubsection{Teacher - Pupil Relationship}

EC is a relational approach. Responses to the ECEQ were analyzed in terms of relationship changes or benefits between adults and pupils. Overwhelmingly, the improved development of trust emerged as a major theme. This was viewed as integral to improvement in pupil-teacher relationships: "the children are more confident to put trust into the adults as we are labelling their emotions and then bringing them to a calm feeling".

Relationships changes were believed to be the result of improved empathetic understanding of observed pupil 
behaviors, enabling staff to better support the labeling of child's feelings. Staff believed that this was key in developing positive relationships that culminated in mutual trust. The consequences of pupil's increasing ability to label how they were feeling further promoted positive relationships between adults and pupils. See Fig. (2) for details of the impact of EC on teacher-pupil relationships.

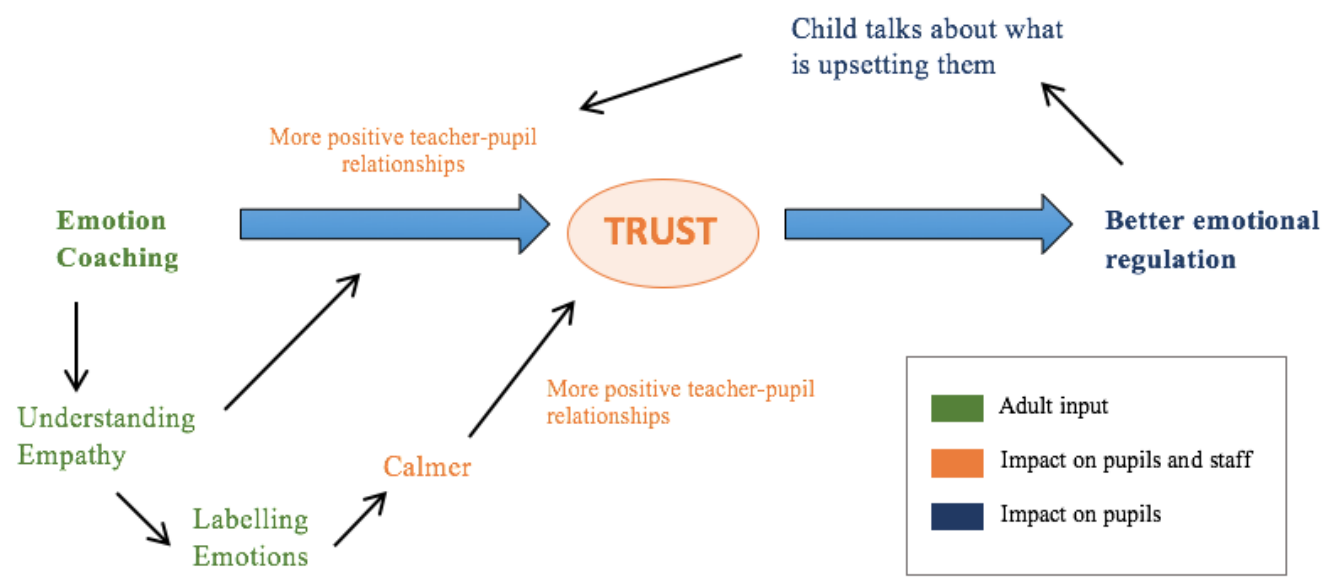

Fig. (2). Diagram showing impact of Emotion Coaching on teacher-pupil relationships.

\subsubsection{Benefits for Families}

Emotion Coaching is used consistently by the school in interactions with families, modeled in front of families with their child, and then explicitly taught to parents/carers individually or via the group training sessions. This consistent and universal approach had a direct effect upon home-school relationships and an indirect effect upon family life.

\subsubsection{Home-School Relationship}

Analysis of data suggest that three practices (attunement, non-judgmental stance towards parents and child, use of the language of emotions) linked to Emotion Coaching are critical to how the school interacts with and involves families in their school.

Attunement is a critical precursor for Emotion Coaching [1]. In a similar manner that this research highlighted that Emotion Coaching promotes trust and positive relationships between staff and pupils, Emotion Coaching also supports trust and positive relationships between home and school. The school staff attune themselves to families by finding out what is important to families, develop bespoke packages of support for each family, and they are quick to respond to communications from families so parents "do not have to hang onto their worries". The nonjudgmental stance is promoted by no blame language, which promotes a sense of community "I tell parents that the school is like a family, you will be in a like-minded group of people who have experienced similar situations".

As a result of the communication style and practices inherent in Emotion Coaching, families were able to take a positive view of their child. Families were able to see their child attending and enjoying school "he runs to the taxi in the mornings", being part of a class, "I've never seen him in a classroom before, he's always been 1:1 in a small room", enjoying their achievements, making friends, and making academic progress, "good for us to see our child happy, making friends and getting an education”.

School responsiveness to family communications empowered families, supported their feelings of competency, and encouraged genuine two-way communication. One parent's request that the school support her child's dental hygiene saw a teeth cleaning regime established as part of the school day. Other parents shared positive experiences: "I took L to the park on her bike and we bought chips on the way home. I never thought I could take her to the park". The two-way communication was supported by the shared use of (emotional) language. This served to increase empathetic interactions and perceptions of similarity in their relationship.

Through the trust that was fostered by effective two-way communication, parents gained a positive view of their child and increased family confidence and self-efficacy. Families then felt able to try Emotion Coaching as a different 
approach to supporting their child at home. The fact that the school was suggesting to home to take a similar approach as they used in school also promoted a sense of similarity, competency and reduced feelings of blame for the family. Successes were easily shared and any difficulties were able to be discussed in a less threatening manner: "if there's something really tough at home that we don't know how to deal with, can we call you?" Fig. (3) gives a pictorial representation of how EC promoted positive home-school relationships and trust, which enabled home and school to develop common practice.

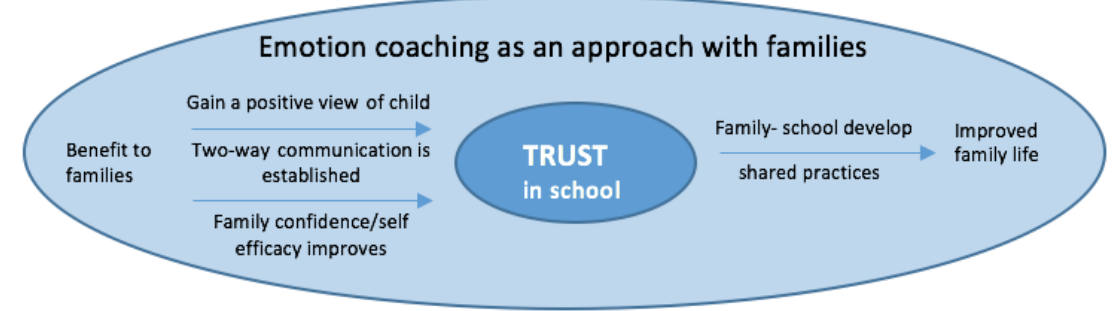

Fig. (3). Effect of Emotion Coaching on families.

\subsubsection{Family Life}

Family life changed in a number of ways: Emotion Coaching started to be used at home, language changed, and the use of punishments decreased: "I cut down on shouting at $T$ when difficult situations arise". A mother noticed the difference in her son's ability to regulate his emotions, "although he does get frustrated and still shouts he never now physically attacks me when it used to be a daily occurrence.....I am no longer concerned that anyone will get seriously hurt [in altercations with siblings]".

For many families the fact that their child was able to access full-time schooling and remain in school all day was significant. Families related how they started to be able to live "normal" lives. For example, they indicated that the children, and therefore the parents, were sleeping better, as a result, "I feel human again." Families also highlighted that they were able to go out in public together and parents were able to maintain their employment and start studies. One father recounted that his business was saved, as he did not need to keep coming to school to collect his son in the middle of a day because of a disruptive school "incident." The lack of phone calls about disruptive behavioral incidents from school during the day also meant a mother felt more confident about being able to start a college course. This has resulted in her being able to concentrate on her studies, and she will soon have a new qualification.

\section{DISCUSSION}

\subsection{Children}

In this school, pupil's ability to regulate their emotions improved as a result of Emotion Coaching, enabling them to better understand and manage their emotions. As a result, there were fewer instances of the need to use physical restraint; less time needed to calm pupils down; more instances of pupils employing positive ways of dealing with problems; and an increased capacity of pupils to accept positive comments about themselves. These results are consistent with previous findings of Emotion Coaching in schools by Rose et al. [34, 45], EC by parents [62, 37], and within the general field of emotion regulation [39].

In this study a significant factor in the development of improved emotion regulation was children's ability to use speech to identify and describe their emotions. This is consistent with literature on the development of emotional competence; children who are able to label negative experiences that affect them emotionally can regulate these emotions more easily [39, 62]. Emotion Coaching also promoted more positive relationships between staff members and pupils; This is consistent with that reported by Rose et al. [34, 45]. Emotion Coaching allowed pupils to develop increased trust of staff members, which resulted in children's emotions being better regulated. The growth in trust could be viewed as an indicator of improved attachment relationships with the school, as Lewicki [63] noted, trust is "the glue the holds relationships together." [63, p. 92]

During the second (Spring) school term the number of instances of physical interventions used by staff was reduced by nearly half, and this level of intervention has been maintained. As a result of pupils' better emotional regulation, and 
therefore pupils being emotionally prepared to learn in the classroom, pupils' rate of academic progress has accelerated. Attainments in reading and numeracy were significantly higher than expected norms for pupil progress in a mainstream school. Even writing progress, which is often difficult for children with SEMH difficulties, was within the expected range for pupils without statements in a mainstream school. The improved academic attainments are consistent with that reported by Rose et al. [45]. We suggest that the academic progress results have good external validity and are robust, in that comparison with national norms or controls were made, in addition to the pre and post intervention internal analysis. However, we are aware of the small number of participants within this one case study

\subsection{Staff}

It would appear that the introduction of Emotion Coaching contributed to reducing staff stress levels. Staff felt that the comprehensive and on-going support and training provided by their SLT on Attachment, Trauma, and Emotion Coaching was important in the development of their personal and professional ability to manage children's behavior. Staff felt that following the introduction of whole school EC they were "calmer", "more in control when a child was in crisis," and "more confident in dealing with children." The reduction of incidents by half where staff need to physically restrain children was a positive outcome for pupils and staff alike. Feelings of improved practice effectiveness are consistent with Rose et al. [34, 45] and mitigate against what Jennings and Greenberg [64] referred to as the teacher "burnout cascade" (p. 492). The staff felt a sense of togetherness, in that that they were "all working towards the same outcome and are a united team." As a result, staff morale and feelings of effectiveness improved and staff absences in the year following the introduction of Emotion Coaching were noticeably fewer.

\subsection{Families}

For many of the families in the school, their prior experience of the education system left them feeling as isolated and rejected as their child. Through attuned and empathic non-judgmental interactions with school, EC as a holistic approach enabled families: to not feel blamed, enabled genuine two-way communication to become established, to develop a shared use of (emotional) language, to develop a positive view of their child, and to start to see themselves as more effective parents/carers. This led to families developing trust in the school. This is consistent with the views of home-school trust by Dunst et al., Adams and Christenson and Francis et al. [17 - 19]. As a result of the trust, families were receptive to the ideas promoted by the school about Emotion Coaching, and Emotion Coaching was able to become common practice for home and school.

It would be inappropriate and unscientific to suggest that it was the whole school Emotion Coaching approach that was causal to the improvements that parents noticed at home. There are too many unaccountable extraneous variables within family life and from the school culture, such as the no-exclusions policy and the farm-based activities. However, non-exclusions policies are supported by staff feeling confident and effective in their approaches to supporting children's behavior at school.

With the establishment of family trust in schools, when Emotion Coaching is shared intentionally as part of training sessions for parents and via modelling in everyday encounters, Emotion Coaching enhances parental self-efficacy and parental understanding about the importance of adult emotional regulation. Parents appreciate the simple structure and steps of Emotion Coaching.

\section{LIMITATIONS}

Limitations in this study include the small number of participants. This affects the credibility and the ability to generalize the findings of this study to other schools and settings. However, the results do corroborate to reflect perceived changes from a whole school setting and are consistent. The accurate tracking of pupil progress over time was hampered by a lack of historical data and pupils moving to different schools. Accurate measures of the actual effect of EC can only be surmised, as it is impossible to exclude the contribution and accumulative effects of extraneous variables, such as the very different nature of the case study school's environment, farm-school, very small numbers of pupils, very high staff-to-pupil ratio, and the impact of effective leadership. The fact that a single case study was selected on the basis of positive reports means that caution needs to be exercised with regards to generalization and bias.

The study employed an outcomes evaluation approach. One of the challenges of using this approach is that in the search for 'what works' the importance of context can be minimized and 'what didn't work' is glossed over [50]. The challenges presented by EC were not addressed as part of this evaluation. 
Both qualitative and quantitative data were collected for this study. The possibility of bias in the selection and collection of data needs to be considered. Data were predominantly collected as a result of an interview with one staff member - the head teacher. This team member's particular perspective on the central question, "Is anyone better off?" led the data gathering process. Power differences also could have played a role in the data that were collected. Asking families if they had noticed any changes at home could be pre-emptive, maybe parents were sensitized to the importance of having a good relationship with the school and their answers reflected a desire to please. Bias in the analysis of data also needs to be considered. However, this is a case study involving interpretive research. Positionality will naturally occur and it is the singleness of the subject and the interpretation and analysis that is important [51,56].

The case study for this research was a single, specialist SEMH primary school. This was the first occasion EC as a whole-school approach had been evaluated. Further research that looks at whole-school outcomes in other types and sizes of educational provisions are needed, such as secondary, mainstream, and other specialist settings; studies that incorporate the use of control schools; and longitudinal studies to capture Emotion Coaching over time. In addition, research that explores the critical factors needed to implement Emotion Coaching as a whole-school approach is needed to evidence support and further promote take-up by schools.

\section{CONCLUSION}

With respect to pupils, families, and school staff well-being, Emotion Coaching enabled the pupils to use psychological resources more effectively to meet the psychological and social challenges education places upon them. Pupils' increased competency in understanding and managing their own emotions and a gradual increase in selfregulation was believed to be related to increased trust levels between adult and pupil. Pupils became emotionally ready to learn and there was marked acceleration in attainments across literacy and numeracy for the pupils. School staff felt more confident in their ability to support their pupils and positive relationships enabled teacher-pupil trust to develop. Family life improved and home-school relationships were characterised by trust and effective communication. This supported the use of Emotion Coaching at home.

A high degree of attention by SLT on supporting staff uptake of Emotion Coaching and whole-school practice was key in enabling staff to feel that they had developed skills and techniques to support pupils' emotional regulation. Initial and ongoing training and supervision supported and sustained a common use of language that then extended to families.

\section{ETHICS APPROVAL AND CONSENT TO PARTICIPATE}

Not applicable.

\section{HUMAN AND ANIMAL RIGHTS}

No Animals/Humans were used for studies that are base of this research.

\section{CONSENT FOR PUBLICATION}

Not applicable.

\section{CONFLICT OF INTEREST}

Some authors of this paper are co-founders of Emotion Coaching UK which provides practitioner training in Emotion Coaching.

\section{ACKNOWLEDGEMENTS}

Declared none.

\section{APPENDIX A}

\section{Interview Questions}

- How have you used/implemented Emotion Coaching with staff and families?

- How is pupil/staff skill/knowledge better off since introducing Emotion Coaching?

- How is pupil/staff attitude opinion better off since introducing Emotion Coaching? 
- How is pupil/staff behavior better off since introducing Emotion Coaching?

- How is pupil/staff/family circumstance better off since introducing Emotion Coaching?

\section{APPENDIX B}

\section{Interview Questions for Telephone Interview Between Head Teacher and Parent/Carer}

- Tell me about your child's behavior at home since starting at our school

- What effect has this had on others in the family?

- What effect has this had on family life?

\section{APPENDIX C}

National Curriculum Sublevels of Attainment Progress Made by Children Following the Introduction of Emotion Coaching.

\begin{tabular}{|c|c|c|c|c|}
\hline Child & $\begin{array}{c}\text { Reading (Sublevel of } \\
\text { progress in 2 years) }\end{array}$ & $\begin{array}{c}\text { Writing (Sublevel of } \\
\text { progress in 2 years) }\end{array}$ & $\begin{array}{c}\text { Mathematics (Sublevel of } \\
\text { progress in 2 years) }\end{array}$ & $\begin{array}{c}\text { Nationally expected sublevel of progress } \\
\text { over two years for all primary aged } \\
\text { children }\end{array}$ \\
\hline $1^{*}$ & 4 & 3 & 6 & 3 \\
\hline 2 & 8 & 4 & 7 & 3 \\
\hline 3 & 8 & 5 & 4 & 3 \\
\hline $4 *$ & 3 & 2 & 3 & 3 \\
\hline 5 & 8 & 7 & 6 & 3 \\
\hline 6 & 5 & 3 & 6 & 3 \\
\hline $7 *$ & 4 & 1 & 5 & 3 \\
\hline 8 & 10 & 6 & 3 & 3 \\
\hline 9 & 6 & 4 & 4 & 3 \\
\hline 10 & 7.44 & 3.88 & 3.88 & \\
\hline Average & 7 & 3 & 3 \\
\hline
\end{tabular}

Pupils whose statement of special educational needs also specified an additional specific learning difficulty (dyslexia) are marked by $*$. ${ }^{1}$ The term 'child' and 'children' will be used in general and family contexts whilst 'pupils' will be used for specific educational contexts. 'Families' is used mainly instead of 'parents/carers.' ${ }^{2}$ A 'small holding' is a small farm. In this instance, 6 acres with animals and crops.

\section{REFERENCES}

[1] Gottman JM, Katz LF, Hooven C. Meta-emotion: How families communicate emotionally. Mahwah, NJ: Lawrence Erlbaum Associates 1997.

[2] Sebba J, Berridge D, Luke N, et al. The educational progress of looked after children in England: Linking care and educational data. Oxford, United Kingdom: Nuffield Foundation 2015.

[3] Cooper P, Cefai C. Evidence-based approaches to social, emotional and behavior difficulties in schools. KEDI J Educ Policy 2013; 10(3): 81-101.

[4] Hart R. Classroom behaviour management: Educational psychologists' views on effective practice. Emot Behav Difficulties 2010; 15(4): 353-71. [http://dx.doi.org/10.1080/13632752.2010.523257]

[5] Epstein JL. Effects on student achievement of teachers' practices of parent involvement Advances in reading/language research: Literacy through family, community, and school interaction. Greenwich, CT: JAI Press 1991; Vol. 5: pp. 261-76.

[6] Dusi P. The family-school relationships in Europe: A research review. Center for Educational Policy Studies Journal 2012; 2(1): 13-32.

[7] Department for Education. Special Needs and Disability Code of Practice: Available from: https://www.gov.uk/government/publications/send-code-of-practice-0-to-25 2013; (0-25):

[8] Engel GL. The need for a new medical model: a challenge for biomedicine. Science 1977; 196(4286): 129-36. [http://dx.doi.org/10.1126/science.847460] [PMID: 847460]

[9] Rees G, Bradshaw J, Goswami H, Keung A. Understanding children's well-being: A national survey of young people's well-being. London, United Kingdom: The Children's Society 2010.

[10] McLaughlin C, Clarke B. Relational matters: A review of the impact of school experience on mental health in early adolescence. Educ Child Psychol 2010; 27(1): 91-103. 
[11] Bronfenbrenner U. The ecology of human development: Experiences by nature and design. Cambridge, MA: Harvard University Press 1979.

[12] Department for Education. Mental health and behaviour in schools: Departmental advice for school staff; [Available from: https:/www.gov.uk/government/ uploads/system/ uploads/attachment_data/ file/416786/ Mental_Health_and_Behaviour__Information_and_Tools_for_Schools_240515.pdf 2014.

[13] Department for Education. Permanent and fixed period exclusions in England 2013 to 2014; [Available from: https://www.gov.uk/government/uploads/ system/uploads/attachment_data/file/449433/SFR27_2015_Text.pdf 2015.

[14] Stormshak EA, Dishion TJ. An ecological approach to child and family clinical and counseling psychology. Clin Child Fam Psychol Rev 2002; 5(3): 197-215. [http://dx.doi.org/10.1023/A:1019647131949] [PMID: 12240707]

[15] Stormshak EA, Brown KL, Moore KJ, Dishion T, Seeley J, Smolkowski K. Going to scale with family-centered, school-based interventions: Challenges and future directions.Family-School Partnerships in Context. Switzerland: Springer International Publishing 2016 ; pp. 25-44. [http://dx.doi.org/10.1007/978-3-319-19228-4_2]

[16] Garbacz SA, McIntosh K, Eagle JW, Dowd-Eagle SE, Hirano KA, Ruppert T. Family engagement within schoolwide positive behavioral interventions and supports. Prev Sch Fail 2016; 60(1): 60-9. [http://dx.doi.org/10.1080/1045988X.2014.976809]

[17] Dunst CJ, Johanson C, Rounds T, Trivette CM, Hamby D. Characteristics of parent-professional partnerships. In: Christenson SL, Conoley JC, Eds. Home-school collaboration: Enhancing children's academic and social competence. Silver Spring, MD: National Association of School Psychologists 1992; pp. 157-74.

[18] Adams KS, Christenson SL. Trust and the family-school relationship examination of parent-teacher differences in elementary and secondary grades. J Sch Psychol 2000; 38(5): 477-97. [http://dx.doi.org/10.1016/S0022-4405(00)00048-0]

[19] Francis GL, Blue-Banning M, Haines SJ, Turnbull AP, Gross JM. Building “our school”: Parental perspectives for building trusting family-professional partnerships. Prev Sch Fail 2016; 60(4): 329-36. [http://dx.doi.org/10.1080/1045988X.2016.1164115]

[20] McCormick MP, Cappella E, O’Connor EE, McClowry SG. Parent involvement, emotional support, and behavior problems: An ecological approach. Elem Sch J 2013; 114(2): 277-300.

[http://dx.doi.org/10.1086/673200]

[21] Christenson S, Sheridan SM, Eds. Schools and families: Creating essential connections for learning. New York: Guilford Press 2001.

[22] Fan W, Williams CM. The effects of parental involvement on students' academic self efficacy, engagement and intrinsic motivation. Educ Psychol 2010; 30(1): 53-74 [http://dx.doi.org/10.1080/01443410903353302]

[23] Marroquín B. Interpersonal emotion regulation as a mechanism of social support in depression. Clin Psychol Rev 2011; 31(8): 1276-90. [http://dx.doi.org/10.1016/j.cpr.2011.09.005] [PMID: 21983267]

[24] Rimé B. The social sharing of emotion as an interface between individual and collective processes in the construction of emotional climates. J Soc Issues 2007; 63(2): 307-22. [http://dx.doi.org/10.1111/j.1540-4560.2007.00510.x]

[25] Rimé B. Emotion elicits the social sharing of emotion: Theory and empirical review. Emot Rev 2009; 1(1): 60-85. [http://dx.doi.org/10.1177/1754073908097189]

[26] Jones SM, Bouffard SM. Social and emotional learning in schools: From programs to strategies. Soc Policy Rep 2012; 26(4): 3-22.

[27] Banerjee R, Weare K, Farr W. Working with 'social and emotional aspects of learning (SEAL): Association and school ethos, pupils social experiences, attendance and attainment. Br Educ Res J 2014; 40: 718-42. [http://dx.doi.org/10.1002/berj.3114]

[28] Durlak JA, Weissberg RP, Dymnicki AB, Taylor RD, Schellinger KB. The impact of enhancing students' social and emotional learning: a meta-analysis of school-based universal interventions. Child Dev 2011; 82(1): 405-32. [http://dx.doi.org/10.1111/j.1467-8624.2010.01564.x] [PMID: 21291449]

[29] Wilson SJ, Lipsey MW. School-based interventions for aggressive and disruptive behavior: update of a meta-analysis. Am J Prev Med 2007; 33(2)(Suppl.): S130-43.

[http://dx.doi.org/10.1016/j.amepre.2007.04.011] [PMID: 17675014]

[30] Vostanis P, Humphrey N, Fitzgerald N, Deighton J, Wolpert M. How do schools promote emotional well being among their pupils? Findings from a national scoping survey of mental health provision in English schools. Child Adolesc Ment Health 2013; 18(3): 151-7. [http://dx.doi.org/10.1111/j.1475-3588.2012.00677.x]

[31] Parker R, Rose J, Gilbert L. Attachment aware schools: An alternative to behaviourism in supporting children's behaviour?The Palgrave International Handbook of Alternative Education. London, United Kingdom: Palgrave Macmillan 2016; pp. $463-83$. [http://dx.doi.org/10.1057/978-1-137-41291-130]

[32] Gilbert L. The transference of Emotion Coaching into community and educational settings. Unpublished PhD [thesis]. Bath Spa University; forthcoming: Bath, United Kingdom: forthcoming 
[33] Gus L, Rose J, Gilbert L. Emotion coaching: A universal strategy for supporting and promoting sustainable emotional and behavioural wellbeing. Educ Child Psychol 2015; 32(1): 31-41.

[34] Rose J, McGuire-Snieckus R, Gilbert L. Emotion Coaching-a strategy for promoting behavioural self-regulation in children/young people in schools: A pilot study. Europ J Social Behav Sci 2015; 13(2): 1766-90. [http://dx.doi.org/10.15405/ejsbs.159]

[35] Gottman JM, Katz LF, Hooven C. Parental meta-emotion philosophy and the emotional life of families: Theoretical models and preliminary data. J Fam Psychol 1996; 10(3): 243-68. [http://dx.doi.org/10.1037/0893-3200.10.3.243]

[36] Havighurst SS, Duncombe M, Frankling E, Holland K, Kehoe C, Stargatt R. An emotion-focused early intervention for children with emerging conduct problems. J Abnorm Child Psychol 2015; 43(4): 749-60. [http://dx.doi.org/10.1007/s10802-014-9944-z] [PMID: 25249470]

[37] Katz LF, Windecker-Nelson B. Parental meta-emotion philosophy in families with conduct-problem children: Links with peer relations. J Abnorm Child Psychol 2004; 32(4): 385-98. [http://dx.doi.org/10.1023/B:JACP.0000030292.36168.30] [PMID: 15305544]

[38] Chen FM, Lin HS, Li CH. The role of emotion in parent-child relationships: Children's emotionality, maternal meta-emotion, and children's attachment security. J Child Fam Stud 2012; 21(3): 403-10. [http://dx.doi.org/10.1007/s10826-011-9491-y]

[39] Barrett LF, Gross J, Christensen TC, Benvenuto M. Knowing what you're feeling and knowing what to do about it: Mapping the relation between emotion differentiation and emotion regulation. Cogn Emotion 2001; 15(6): 713-24. [http://dx.doi.org/10.1080/02699930143000239]

[40] Schore AN. Affect regulation and the origin of the self: The Neurobiology of emotional development. Hillsdale, NJ: Lawrence Erlbaum Associates 1994.

[41] Siegel DJ. Toward an interpersonal neurobiology of the developing mind: Attachment relationships, "mindsight," and neural integration. Infant Ment Health J 2001; 22(1-2): 67-94. [http://dx.doi.org/10.1002/1097-0355(200101/04)22:1<67::AID-IMHJ3>3.0.CO;2-G]

[42] Department for Education. Behaviour and discipline in schools: Advice for headteachers and school staff; 2014 [Available from: https://www.gov.uk/government/ Behaviour_and_discipline_in_schools_guidance_for_headteachers_and_staff.pdf 2014

[43] Department for Education. School behaviour and attendance: Research priorities and questions; 2014 [Available from: https://www.gov.uk/government/

Behaviour_and_school_attendance_research_priorities_and_questions.pdf. 2014.

[44] Office for Standards in Education. Below the radar: Low-level disruption in the country's classrooms. Manchester, United Kingdom: Ofsted; [Available from: https:/www.gov.uk/government/ uploads/system/uploads/ attachment_data/ file/379249/Below 20the 20radar 20_201owlevel_20disruption_20in_20the_20country_E2_80_99s_20classrooms.pdf 2014 .

[45] Rose J, McGuire-Snieckus R, Wood F. Impact evaluation of the attachment aware schools project for Stoke virtual school: A pilot study. Bath, United Kingdom: Institute for Education, Bath Spa University 2016.

[46] Stake RE. Case studies.Handbook of Qualitative Research. Thousand Oaks, CA: Sage 1994; pp. $236-47$.

[47] Bassey M. Case study research in educational settings. Maidenhead, Berkshire, United Kingdom: Open University Press 2009.

[48] Yin RK. Case study research: Design and methods. Thousand Oaks, CA: Sage 2013.

[49] Friedman M. Trying hard is not good enough: How to produce measurable improvements for customers and communities. Victoria, Canada: Trafford Publishing 2005 .

[50] Hoggarth L, Comfort H. A practical guide to outcome evaluation. London, United Kingdom: Jessica Kingsley 2010.

[51] Thomas G. How to do your case study. Thousand Oaks, CA: Sage 2010.

[52] Swanbourne P. Case study research. London, United Kingdom: Sage 2010.

[53] Willig C. Introducing qualitative research in psychology. 3rd ed. Maidenhead, United Kingdom: Open University McGraw-Hill 2013.

[54] Denscombe M. The good research guide for small-scale social research projects. 4th ed. Maidenhead, United Kingdom: Open University McGraw-Hill 2010.

[55] Hammersley M, Gomm R. Introduction.Case Study Method. London, United Kingdom: Sage 2000; pp. 1-16.

[56] Thomas G. How to do your research project: A guide for students in education and applied social sciences. Thousand Oaks, CA: Sage 2013.

[57] Creswell JW, Plano Clark VL. Designing and conducting mixed methods research. Thousand Oaks, CA: Sage 2011.

[58] Chamberlain T, Golden S, Walker F. Executive summary: Implementing outcomes based accountability in children's services, an overview of the process and impact. Slough: National Foundation for Educational Research 2010. https://www.nfer.ac.uk

[59] Bovaird T. Attributing outcomes to social policy interventions-'Gold standard' or 'fool's gold' in public policy and management? Soc Policy Adm 2014; 48(1): 1-23. 
[http://dx.doi.org/10.1111/j.1467-9515.2012.00869.x]

[60] Department for Education. Statistical release, children with special educational needs 2013: An analysis; 2013. [Available from: http://www.education.gov.uk 2013. SFR42/2013

[61] Robson C. Real world research. Oxford, United Kingdom: Blackwell 2002.

[62] Havighurst SS, Wilson KR, Harley AE, Kehoe C, Efron D, Prior MR. "Tuning into Kids": reducing young children's behavior problems using an emotion coaching parenting program. Child Psychiatry Hum Dev 2013; 44(2): 247-64.

[http://dx.doi.org/10.1007/s10578-012-0322-1] [PMID: 22820873]

[63] Lewicki RJ, Wiethoff C. Trust, trust development, and trust repair.The Handbook of Conflict Resolution: Theory and Practice. San Francisco, CA: John Wiley \& Sons 2006; pp. 92-119.

[64] Jennings PA, Greenberg MT. The prosocial classroom: Teacher social and emotional competence in relation to student and classroom outcomes. Rev Educ Res 2009; 79(1): 491-525.

[http://dx.doi.org/10.3102/0034654308325693]

(C) 2017 Gus et al.

This is an open access article distributed under the terms of the Creative Commons Attribution 4.0 International Public License (CC-BY 4.0), a copy of which is available at: https://creativecommons.org/licenses/by/4.0/legalcode. This license permits unrestricted use, distribution, and reproduction in any medium, provided the original author and source are credited. 